\title{
Tax Buoyancy in Sub-Saharan Africa and its Determinants
}

\author{
Sanjeev Gupta ${ }^{1} \cdot$ João Tovar Jalles ${ }^{2,3,4,5} \cdot$ Jianhong Liu ${ }^{6}$ (D
}

Accepted: 14 August 2021 / Published online: 21 September 2021

(C) The Author(s), under exclusive licence to Springer Science+Business Media, LLC, part of Springer Nature 2021

\begin{abstract}
In this paper, we estimate short- and long-term tax buoyancy for 44 sub-Saharan African (SSA) countries during 1980-2017 using time series and panel techniques. We find that the long-term tax buoyancy is either one or slightly above one for most SSA countries. Fragile states have a lower short-term tax buoyancy reflecting their institutional weaknesses. Short-term buoyancy of personal income tax is significantly less than one. Both short- and long-run tax responses are lower than those reported in previous cross-country studies, which can be interpreted as a reduced power of both automatic stabilization in the short run and fiscal sustainability in the long run. We find that central government debt and shadow economy exert a downward pressure on tax buoyancy. An important implication of these results is that the current tax systems in SSA would not be able to generate domestic revenues to the extent needed for financing the Sustainable Development Goals (SDGs).
\end{abstract}

Keywords Tax buoyancy · Sustainable Development Goals · Error Correction Model $\cdot$ Sub-Saharan Africa

Jianhong Liu

jh.liu0226@gmail.com

Sanjeev Gupta

sgupta@cgdev.org

João Tovar Jalles

joaojalles@gmail.com

1 Center for Global Development, 2055 L St NW, Washington, DC 20036, USA

2 Instituto Superior de Economia E Gestão (ISEG), Universidade de Lisboa, Rua do Quelhas 6, 1200-781 Lisboa, Portugal

3 Research in Economics and Mathematics (REM) and Research Unit On Complexity and Economics (UECE), ISEG, Universidade de Lisboa, Rua Miguel Lupi 20, 1249-078 Lisbon, Portugal

4 Economics for Policy, Nova School of Business and Economics, Universidade Nova de Lisboa, Rua da Holanda 1, 2775-405 Carcavelos, Portugal

5 IPAG Business School, 184 Boulevard Saint-Germain, 75006 Paris, France

6 Center for Global Development, 2055 L St NW, Washington, DC 20036, USA 
JEL Classification E62 $\cdot \mathrm{H} 20 \cdot \mathrm{H} 24 \cdot \mathrm{H} 25$

\section{Introduction}

One of the seven actions adopted under the Addis Ababa Action Agenda in 2015 calls on developing countries to mobilize more revenues domestically. The underlying rationale is that these additional resources, when supplemented with limited external flows, would help finance the Sustainable Development Goals (SDGs) by 2030. ${ }^{1}$ The International Monetary Fund (IMF) (Gaspar et al., 2019) estimates that on average, low-income countries (LICs) will need additional resources amounting to 15.4 percent of GDP to finance the SDGs in education, health, roads, electricity, and water by 2030 . These resource requirements are even greater in sub-Saharan Africa (SSA) than in a typical low-income country (LIC): The median SSA country faces additional spending of about 19 percent of GDP. Benin and Rwanda, for example, would require additional resources amounting to 21.3 percent of GDP and 18.7 percent of GDP, respectively. In the average LIC, the IMF estimates that of the required additional financing, 5 percentage points of GDP would have to come from domestic taxes.

The question that arises is whether tax revenues in SSA would continue to grow in the future together with economic growth. This would depend on the buoyancy of these countries' tax systems, which captures the response of tax revenues to changes in national income including discretionary changes made by countries to their tax systems. A tax buoyancy of one would imply that a 1 percent increase in GDP would increase tax revenues by 1 percent, thus leaving the tax-to-GDP ratio unchanged. A tax buoyancy exceeding one would result in tax revenues rising by more than the increase in GDP. A buoyancy greater than unity is desirable if the country would like to raise more revenues and to strengthen fiscal stability and support economic development over time. ${ }^{2}$ Discretionary changes may be used to compensate for a low tax buoyancy in a country, but then actual buoyancy may lag the long-term trend. It would be expected that long-run tax buoyancy is greater than one for progressive taxes (such as personal income tax) and lower than one for taxes are that are mostly regressive (such as the value-added tax).

This paper estimates tax buoyancies for 44 SSA countries using both time series and panel data techniques. It relies on the most recent and comprehensive crosscountry revenue dataset available from International Centre for Tax and Development (ICTD)'s Government Revenue Dataset (GRD). ${ }^{3}$ The paper also ascertains

\footnotetext{
${ }^{1}$ The 17 Sustainable Development Goals (SDGs) with 169 targets were adopted by United Nations Member States in 2015 to end poverty, protect the planet and ensure that all people enjoy peace and prosperity by 2030 .

${ }^{2}$ A sustained tax buoyancy of greater than one would imply that the ratio of taxes-to-GDP would increase indefinitely, while a value lower than one would mean that the same ratio would fall continuously. Both cases do not represent a long-run equilibrium for the sustainability of public finances.

${ }^{3}$ ICTD GRD data used in the paper combines data from several different international sources under a standard classification system, including OECD Revenue Statistics, OECD Latin American Tax Statistics, IMF Government Finance Statistics (GFS), IMF Article IV Staff Reports, and CEPALSTAT Rev-
} 


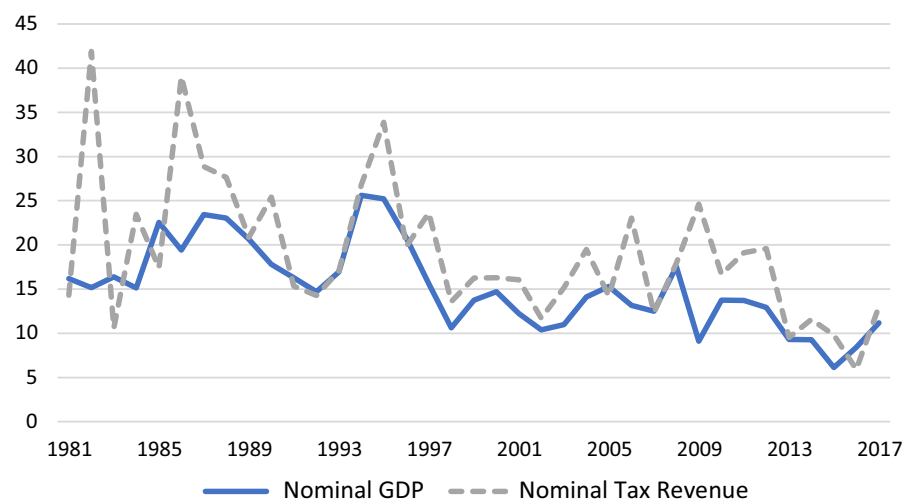

Fig. 1 Growth in Nominal GDP and Nominal Tax Revenues (\%) in Sub-Saharan Africa, 1981-2017. Note: South Sudan, Angola and Democratic Republic of the Congo are excluded due to data non-availability, and result remains unchanged if we exclude Nigeria and South Africa Source: International Centre for Tax and Development (ICTD)'s Government Revenue Dataset

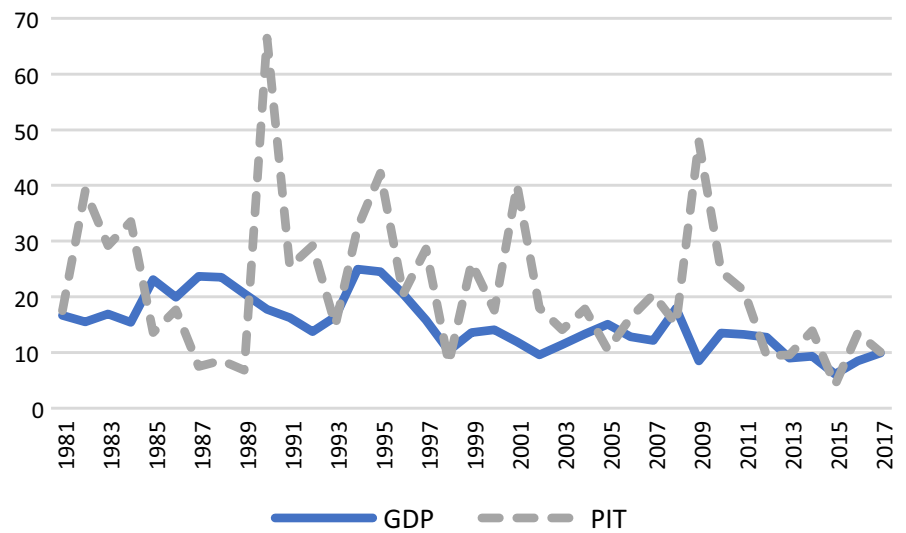

Fig. 2 Growth in Nominal GDP and Personal Income Tax (PIT) (\%) in Sub-Saharan Africa, 1981-2017

whether the recent tax reforms in SSA countries have improved tax buoyancy since the late 1990s. It then concludes that additional tax revenues generated by 2030 using estimated tax buoyancies for SSA would fall short of resources needed to finance the SDGs.

The overall nominal tax revenue and GDP growth for SSA countries are displayed in Fig. 1. In general, nominal revenues seem to have grown faster than nominal GDP. This suggests that on average, tax buoyancy has been greater than

Footnote 3 (continued)

enue Statistics in Latin America, leading to gains in both coverage and accuracy compared to any other single source. The GRD is available from www.ictd.ac as a Microsoft Excel Spreadsheet (.xls), Open Document Spreadsheet (.ods), or Stata data file (.dta). 


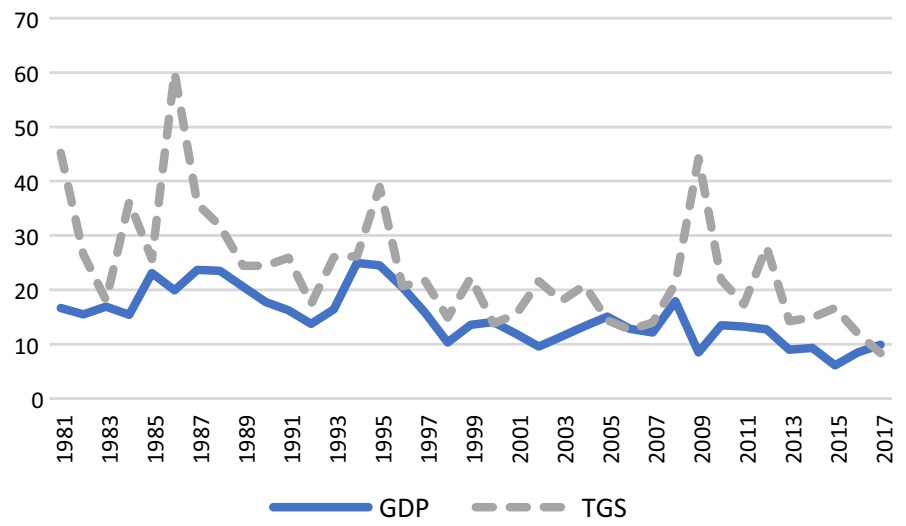

Fig. 3 Growth in Nominal GDP and Taxes on Goods and Services (TGS) (\%) in Sub-Saharan Africa, 1981-2017

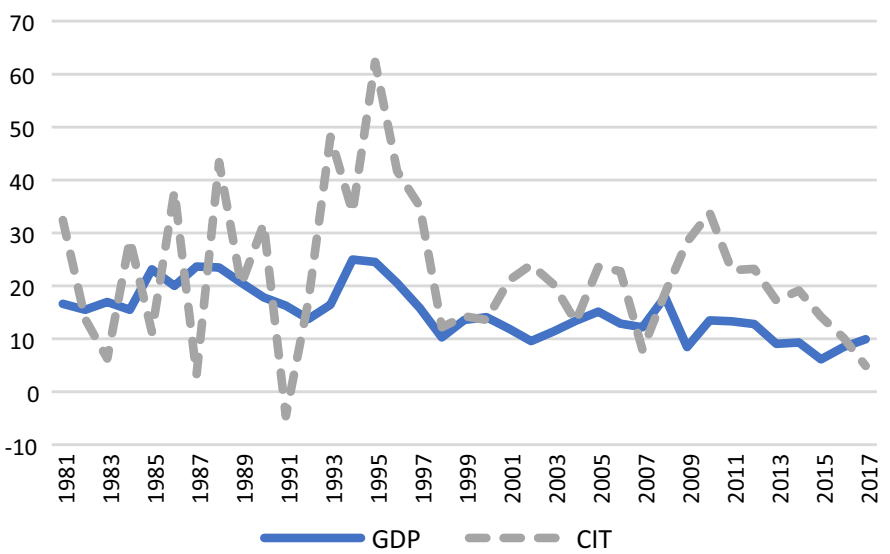

Fig. 4 Growth in Nominal GDP and Corporate Income Tax (CIT) (\%) in Sub-Saharan Africa, 1981-2017

one for most years from 1981 to 2017. Looking in more detail, nominal revenues from personal income tax (PIT) and taxes on goods and services (TGS) seem to have grown faster than nominal GDP (Figs. 2 and 3), while those from corporate income tax (CIT) and trade taxes have maintained the same pace as growth in nominal GDP (Figs. 4 and 5).

There are several country-specific and two cross-country studies on tax buoyancy in SSA (Table 1), as well as several cross-country studies for OECD countries. Over time, econometric methodologies have been improved upon and refined, moving from ordinary least squares (OLS) to instrumental variables (IV) and dynamic OLS estimator to more sophisticated techniques that account for cross-sectional dependence in panel data, such as Mean Group (MG) and Pooled 


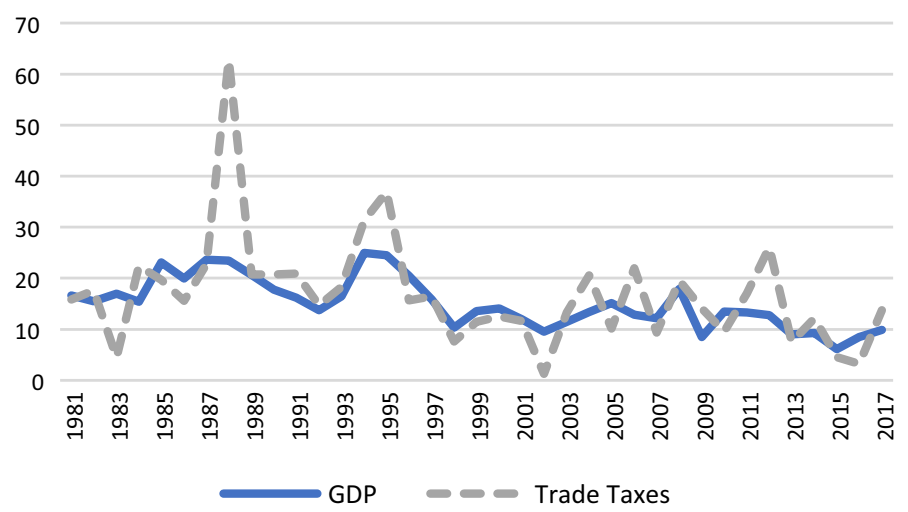

Fig. 5 Growth in Nominal GDP and Trade Taxes (\%) in Sub-Saharan Africa, 1981-2017. Note: South Sudan, Angola, Democratic Republic of the Congo, Eritrea, Liberia, and Nigeria are excluded due to data non-availability. Source: ICTD's Government Revenue Dataset

Mean Group (PMG) (Pesaran \& Smith, 1995; Pesaran et al., 1999). The key features of SSA and selected OECD studies are summarized in Table 1.

The remainder of the paper is structured as follows. Section 2 provides an overview of the tax system in SSA. Section 3 presents the data and econometric framework. Section 4 discusses the empirical results for the long- and short-run tax buoyancies for the SSA as well as for specific countries. Section 5 explores considerations that affect tax buoyancy across countries. Section 6 uses the previously estimated tax buoyancy estimates to calculate additional revenues that would be generated by 2030 in SSA and two countries-Benin and Rwanda, and how they compare with projected resource needs. Section 7 concludes with policy implications and suggestions for future research.

\section{Tax systems in sub-Saharan Africa-an overview}

SSA countries have, on average, made progress in mobilizing more taxes since 2000 (Fig. 6). On average, tax revenues have grown by three percentage points of GDP between 2000 and 2017 (from just around 13 percent to almost 16 percent). However, there is considerable heterogeneity as individual country performance varies: for 17 out of 29 countries, the 2017 tax-to-GDP ratio was less than the average of 16 percent. ${ }^{4}$ In more than half of countries (15), the tax-to-GDP ratio was less than 15

\footnotetext{
4 The 2017 tax-to-GDP ratio is available for 29 countries.

The seventeen countries comprise Central African Republic, Equatorial Guinea, Ethiopia, Gambia, Ghana, Guinea, Guinea-Bissau, Kenya, Liberia, Madagascar, Mali, Niger, Rwanda, Sierra Leone, Tanzania, Uganda, and Zimbabwe.
} 


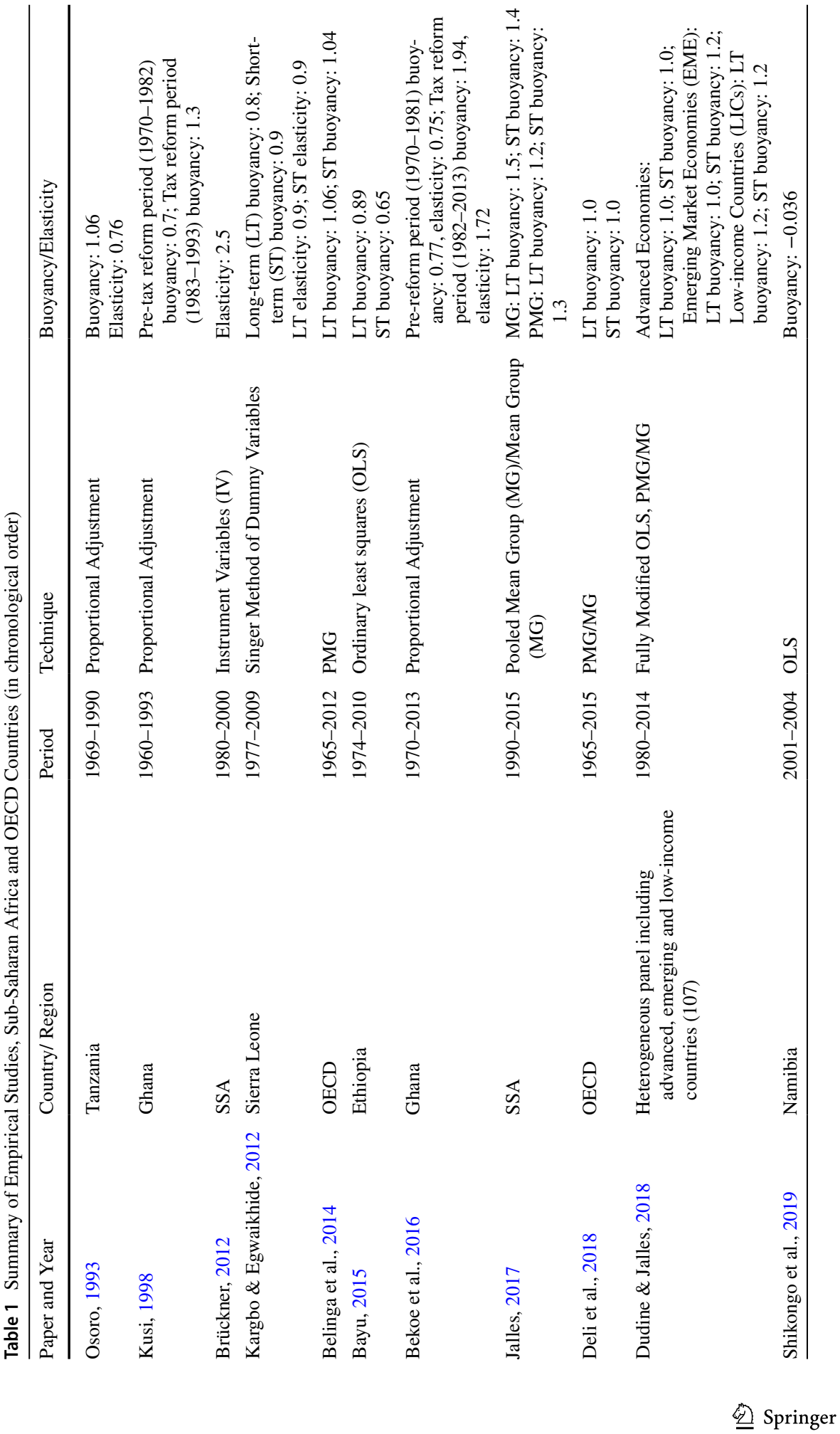




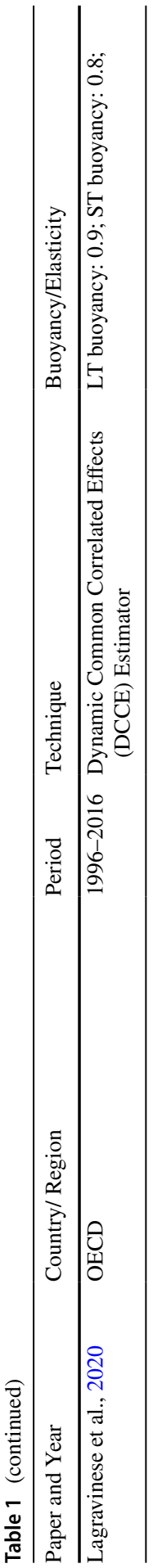

글 Springer 


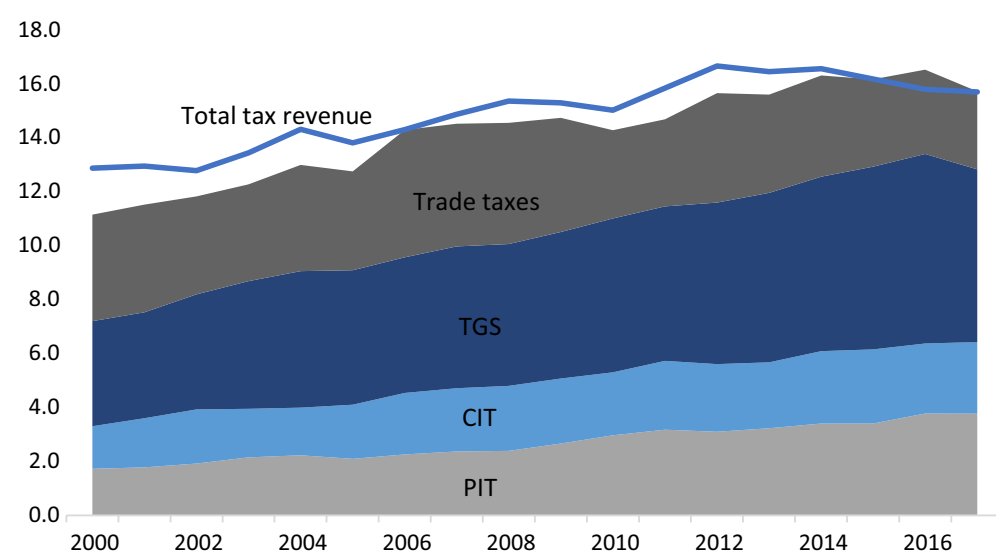

Fig. 6 Unweighted Average of Tax Revenues in sub-Saharan Africa, 2000-2017 (as a percent of GDP). Note: South Sudan is excluded because of non-availability of data; Revenues from different tax types do not necessarily add up to total tax revenue due to different sample sizes. Source: ICTD's Government Revenue Dataset

percent. ${ }^{5}$ This tax capacity is viewed as essential for the state to become viable and ensure sustainable growth (Gaspar et al., 2016).

A significant portion of the increase in tax revenue during this period has come from increasing TGS collections (including VAT). TGS revenues as a share of GDP increased by around 2.5 percent of GDP (Fig. 6). On average, the TGS now constitutes roughly 40 percent of total tax collections in SSA. The widespread adoption of a broad-based consumption tax, such as the VAT, has helped strengthen tax administration in the region, as countries have adopted improved technology, such as electronic filing systems, thereby improving compliance (Mullins, Gupta, \& Liu, 2020). The growth in TGS revenues has been accompanied by a slight fall in average trade tax revenues. Economic literature has shown that a move away from trade taxes in favor of consumption taxes is growth friendly. The share of PIT in relation to GDP increased by 2 percentage points to 4 percent of GDP during the period under study. As a comparison, average PIT in advanced economies is over 8 percent of GDP. This difference is likely due to higher, and more progressive, PIT rates in advanced economies and better collection and enforcement mechanisms (i.e., a smaller share of workers in the informal economy). CIT revenues as a share of GDP increased by 1 percent of GDP. This is consistent with the experience of advanced economies and emerging markets.

5 The 15 countries include Central African Republic, Equatorial Guinea, Ethiopia, Gambia, Ghana, Guinea, Guinea-Bissau, Liberia, Madagascar, Niger, Rwanda, Sierra Leone, Tanzania, Uganda, and Zimbabwe. 


\section{Data and econometric framework}

\subsection{Data}

As explained on page 3 and footnote 7, data for tax revenues come from the Government Revenue Dataset as compiled by ICTD for 44 sub-Saharan African countries for the period 1980 to $2017 .^{6}$ This time period includes the most severe financial and economic crises in many decades, extending between 2007 and 2013. The global financial crisis stressed the tax systems of SSA countries. In addition to buoyancy of aggregate tax revenues, we also focus on four tax categories, namely personal income tax (PIT), corporate income tax (CIT), tax on goods and services (TGS), and trade taxes. Disaggregated data by tax types are available for a smaller number of countries and are of shorter duration. Data on tax revenues are expressed in real terms in local currency units.

\subsection{Empirical framework}

We specify an autoregressive distributed lag (ARDL) model which is used to analyze dynamic relationships with time-series data in a single-equation framework shown in Eq. (1). The ARDL model considers both levels and changes of the relevant variables in order to identify both the long-run growth and short-run variability of tax revenues through a single equation:

$$
\operatorname{lnTax}_{i, t}=\sum_{j=1}^{p} \lambda_{i j} \operatorname{lnTax}_{i, t-j}+\sum_{j=0}^{q} \delta_{i j} \operatorname{lnGDP}_{i, t-j}+\mu_{i}+\varepsilon_{i t}
$$

$\operatorname{Tax}_{i, t}$ denotes tax revenue in country $i$ in year $t, \mathrm{GDP}_{i, t}$ stands for its level of GDP, $\mu_{i}$ is the country-specific effect and $\varepsilon_{i t}$ is the error term-both the tax variables and GDP are expressed in logs.

We follow the existing literature (Belinga et al., 2014; Deli et al., 2018; Dudine $\&$ Jalles, 2018) and use the optimal lag length to be equal to 1 for both $\mathrm{p}$ and $\mathrm{q}$ in Eq. (1), which gives us Eq. (2). ${ }^{7}$ It suggests that developments in tax revenue can be explained by GDP of the current and preceding period, and by tax revenue in the preceding period.

$$
\operatorname{lnTax}_{i, t}=\lambda_{i} \operatorname{lnTax}_{i, t-1}+\delta_{i, 0} \operatorname{lnGDP}_{i, t}+\delta_{i, 1} \operatorname{lnGDP}_{i, t-1}+\mu_{i}+\varepsilon_{i t}
$$

Equation (2) can be transformed into a single error correction model (ECM) of Eq. (3), which shows that changes in tax can be explained by changes in GDP and corrections made in response to the disequilibrium from last period given in the parenthesis.

\footnotetext{
6 South Sudan is excluded because of non-availability of sufficiently long time series.

7 We also extended the lag length to $p=q=2$. Results are shown in the Appendix Table 13 .
} 


$$
\Delta \operatorname{lnTax} \operatorname{Tax}_{i, t}=\gamma_{i}\left(\operatorname{lnTax}_{i, t-1}-\beta_{i} \operatorname{lnGDP}_{i, t-1}\right)+\theta_{i} \Delta \operatorname{lnGDP}_{i, t}+\mu_{i}+\varepsilon_{i t}
$$

where $\theta_{i}$ measures the instantaneous effect of a change in GDP on tax revenue, reflecting the short-term buoyancy of the tax. The parameter $\beta_{i}$ denotes the longterm buoyancy. The parameter $\gamma_{i}$ measures the speed of adjustment, i.e., how fast the system converges to its long-run equilibrium. Application of the error correction model presupposes that tax revenues and GDP are cointegrated. Before estimating Eq. (3), it is thus essential to diagnose both the stationarity and cointegration properties of the different time series.

We follow a two-step empirical strategy in estimating Eq. (3). In the first step, we apply time series techniques to estimate short- and long-term tax buoyancy for SSA countries with adequate data (that is, applying these to those countries with a reasonably continuous set of observations for the variables of interest). As some countries lacked ample data or failed to pass the necessary statistical test, we resorted to the application of panel techniques in the next step. This allowed us to maximize the cross-sectional and time series dimensions and to make use of all available data in estimating tax buoyancy of SSA as a region, which is not possible with time series techniques.

\section{Empirical results}

\subsection{Time series regressions}

For individual countries, we estimate short- and long-term buoyancy for total tax revenues by using time series techniques provided taxes and GDP are found to be cointegrated. ${ }^{8}$ Since sufficiently long disaggregated data on specific tax types are not available, we skip time series estimates for them. We then test whether the long- and short-term buoyancy equals one. Table 2 and Fig. 7 display the estimates for 25 out of 44 SSA countries which passed the cointegration test. ${ }^{9}$ Estimates for the remaining 19 countries are available from authors upon request. ${ }^{10}$

Results suggest an average long-term buoyancy of 1.088. It is significantly smaller than one in three countries (Central African Republic, Equatorial Guinea and Zambia). In five countries (Burundi, Democratic Republic of Congo, Gabon, Guinea-Bissau and Mauritius), the coefficient is not significantly different from one, which means for these eight countries, tax revenue is not growing faster than GDP growth. In the remaining 17 countries, it exceeds one by a small margin.

Results also suggest an average short-term buoyancy of 1.004 which is smaller than the long-term buoyancy. It is significantly smaller than one in 5 countries

\footnotetext{
${ }^{8}$ Results of country specific cointegration tests are available from the authors upon request.

9 The Newey-West estimator is applied to account for autocorrelation and heteroskedasticity in the error terms.

${ }^{10}$ We excluded South Sudan because of non-availability of data. The failure to pass the cointegration tests in 19 countries is probably a reflection of structural changes taking place in these countries.
} 


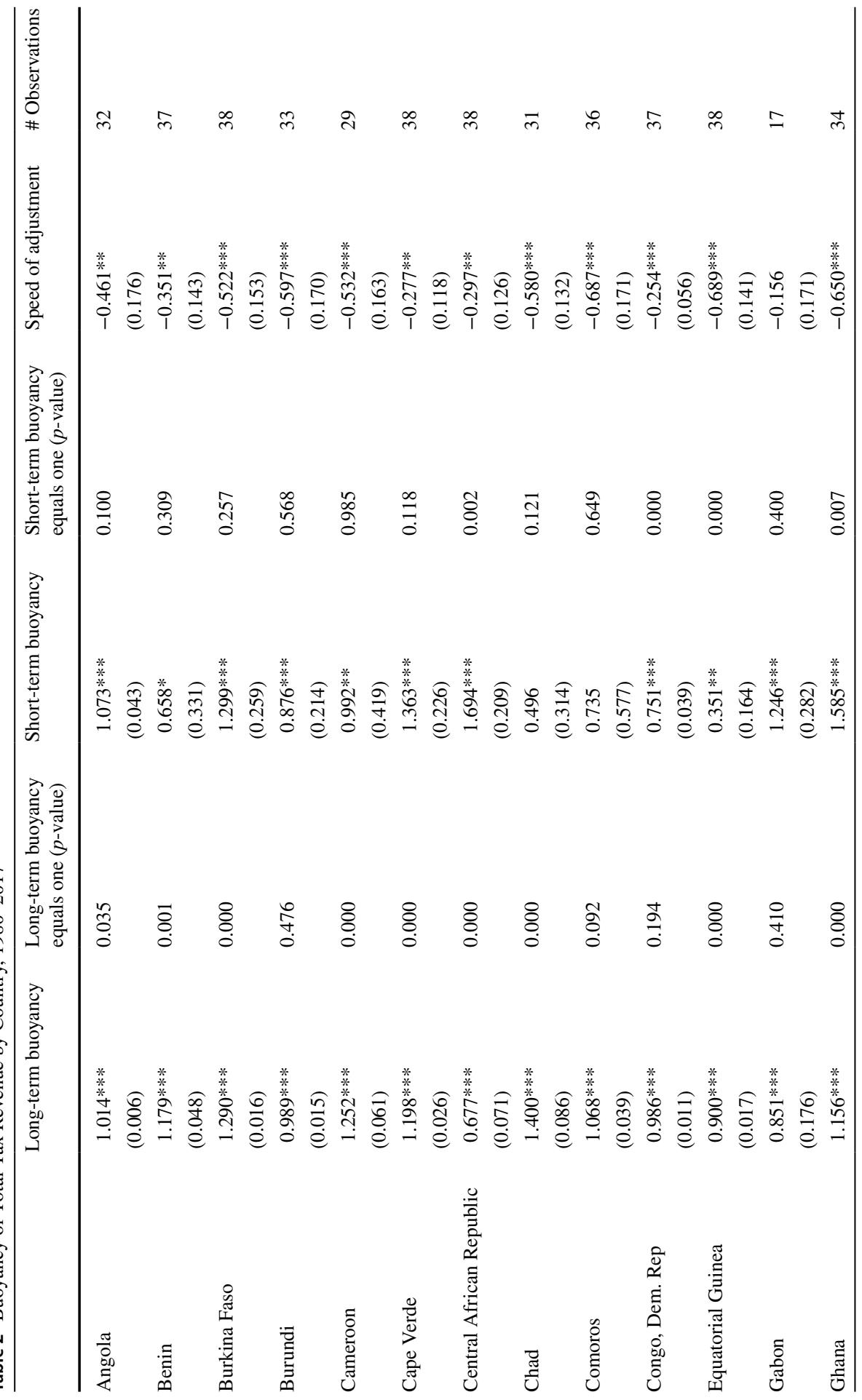




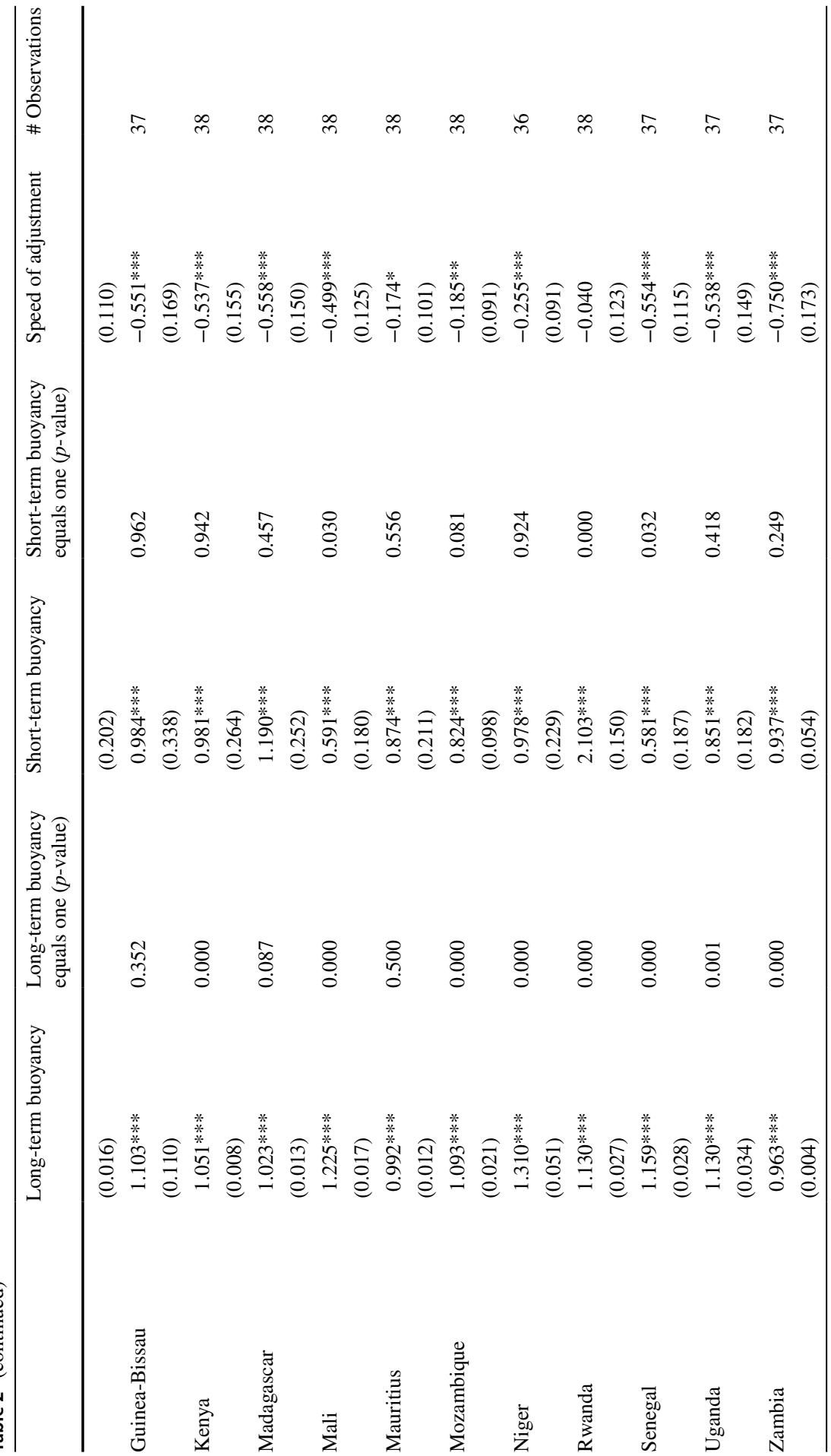




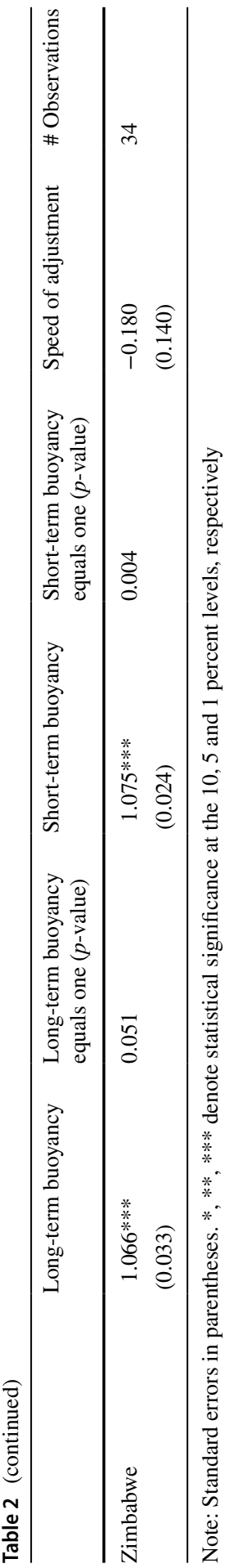




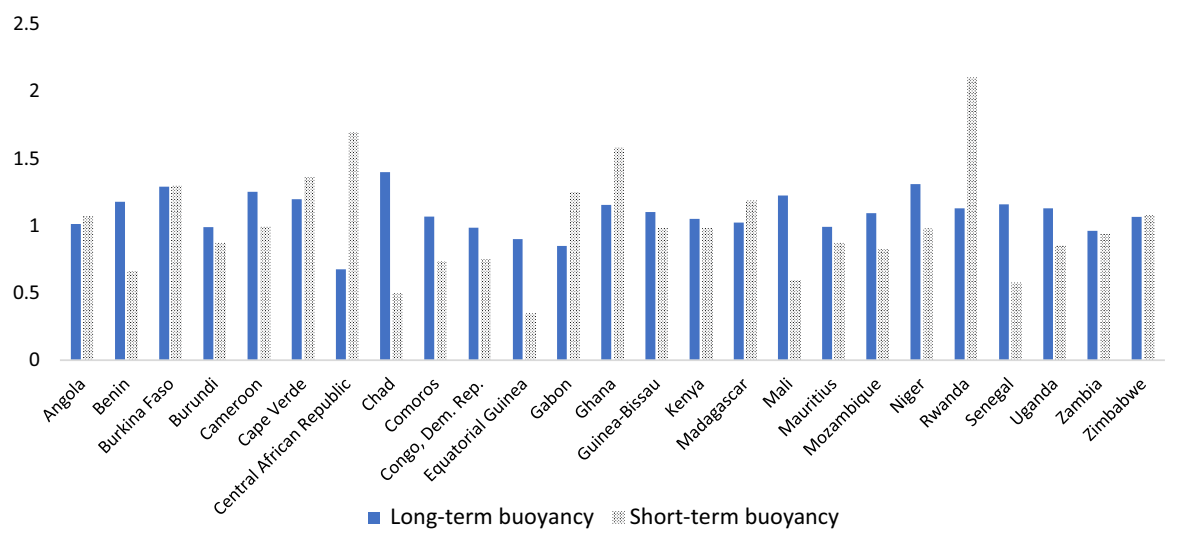

Fig. 7 Country-specific Buoyancy of total tax revenue

(Democratic Republic of Congo, Equatorial Guinea, Mali, Mozambique, and Senegal). In 14 countries, the coefficient is not significantly different from one (Benin, Burkina Faso, Burundi, Cameroon, Cape Verde, Chad, Comoros, Gabon, GuineaBissau, Kenya, Madagascar, Mauritius, Niger, Uganda, and Zambia). This suggests that the tax system in these countries has not been working as a good automatic stabilizer. In the remaining six countries, it significantly exceeds one. The crosscountry variation in short-term buoyancy ranges from 0.351 in Equatorial Guinea to 2.103 in Rwanda. In Central African Republic, Ghana, and Rwanda, the short-term tax revenue buoyancies display a higher reaction to the economic cycle than average which suggests their tax systems have been working as a good automatic stabilizer. Notwithstanding its high short-term buoyancy, Central African Republic could not guarantee fiscal sustainability in the long run indicated by its significantly lower long-term buoyancy. This may be due to a general decline in the progressivity of its tax system. Benin, on the other hand, showcases a higher long-term buoyancy and a lower short-term buoyancy, suggesting that in terms of fiscal sustainability the tax system has the ability to grow in line with the GDP growth.

Also note that the speed of adjustment is negative for all countries and statistically significant for most of them, consistent with convergence to a long-term relationship.

We then group buoyancy estimates into three country groups: fragile, foreign-aid dependent and natural-resource rich and take the mean of individual country estimates. ${ }^{11}$ In theory, the fragile states have less developed fiscal institutions and thus

\footnotetext{
11 Fragile state is defined as one which has a CPIA country rating of 3.2 or less, and/or when there is the presence of a UN and/or regional peacekeeping or political/peace-building mission during the last three years. (The CPIA measures a country's effort to improve its institutions and policies to reduce poverty; country performance is rated on a scale of 1 to 6 , with 1 being weak and 6 being strong.) Foreign aid dependent countries are those which receive aid larger than the median of the sample. When exports of non-renewable natural resources such as oil, minerals and metals account for more than 25 percent of the value of the country's total exports, it is defined as natural-resource-rich.
} 
Table 3 Buoyancy of total tax revenue across different groups

\begin{tabular}{lll}
\hline & $\begin{array}{l}\text { Long-term buoy- } \\
\text { ancy }\end{array}$ & $\begin{array}{l}\text { Short-term } \\
\text { buoyancy }\end{array}$ \\
\hline All countries & 1.088 & 1.004 \\
Fragile & 1.067 & 0.892 \\
Foreign-aid dependent & 1.089 & 1.043 \\
Natural-resource rich & 1.069 & 0.969 \\
\hline
\end{tabular}

Table 4 Parameter Restrictions for Different Estimators

\begin{tabular}{lll}
\hline Estimator & Short-term coefficient & Long-term coefficient \\
\hline Mean Group (MG) & Heterogeneous & Heterogeneous \\
Pooled Mean Group (PMG) & Heterogeneous & Homogeneous \\
Dynamic fixed effects (DFE) & Homogeneous & Homogeneous \\
\hline
\end{tabular}

a weaker capacity to implement taxes. This would suggest that they may have lower tax buoyancies than other countries in the region. The aid-dependent countries may face different incentives in collecting their taxes compared to those who receive little or no aid (Clements et al., 2004; Benedek et al., 2014). In these countries, there may be a disincentive to mobilize domestic revenues because of the availability of aid flows. In the same vein, the tax system of natural-resource-rich countries tends to rely heavily on natural resource revenues which could have implications for nonresource domestic taxes and thus for overall and tax-specific buoyancies (Crivelli \& Gupta, 2014). Empirically, results are broadly similar except for fragile states, where short-term buoyancy is somewhat lower (Table 3).

\subsection{Panel regressions}

\subsubsection{Baseline model}

We estimate Eq. (3) for total tax revenue in a panel environment for our entire sample of SSA countries. ${ }^{12}$ Panel techniques allow us to maximize the country coverage and make use of all data to have a broader picture of tax buoyancy of SSA as a region, which we could not do in the application of time series methods. In this regard, the Pooled Mean Group (PMG) (Pesaran et al., 1999) estimator allows heterogeneity in short-term coefficients across countries but constrains the long-run

\footnotetext{
12 Before proceeding, we conducted panel stationarity tests for GDP and tax revenues. We could not reject the null hypothesis that variables were nonstationary which meant that all these series had a unit root process (see Appendix Table 14). All non-stationary series were transformed into stationary series of order 1 by first differencing them (see Appendix Table 15). We then performed the cointegration and the results are reported in Appendix (Table 14). We conclude that tax revenues are cointegrated with GDP.
} 
coefficients to be equal. That is, it assumes that the long-term relationship between dependent and independent variables is the same across countries. The Mean Group (MG) (Pesaran \& Smith, 1995) estimator, in contrast, allows for full parameter heterogeneity; that is, a separate regression is estimated for each country and an average reported. Both MG and PMG are appropriate for the analysis of dynamic panels with both large time and cross section dimensions, and they have the advantage of accommodating both the long-run equilibrium and the possibly heterogeneous dynamic adjustment process. At the other end of the scale, dynamic fixed effects estimation constrains all short-run and long-run coefficients to be equal across countries (see Table 4 for a summary).

To test the validity of the assumption that the long-run relationship between the growth of GDP and tax revenues is the same across countries, we performed the Hausman test to compare the resulting PMG estimates against those stemming from MG estimator. ${ }^{13}$ Table 5 displays the estimated coefficients using a full panel of $40 \mathrm{SSA}$ countries ${ }^{14}$ for long-term, short-term and the speed of adjustment using both PMG and MG and the resulting Hausman test statistics. For CIT, the PMG procedure produces estimates that are consistent and more efficient and, thus, it is preferred. MG estimator is preferred for remainder of tax components and total tax revenue. Furthermore, coefficient estimates for total tax revenue and PIT under both PMG and MG are broadly similar.

We find that the long-term buoyancy for total tax revenue and most tax components is higher than one, which suggests that most of the levies are progressive, except for trade taxes. Estimates of CIT buoyancies are in the same range as those of the OECD countries. The short-term buoyancy is generally lower, and in one case, PIT, it is significantly lower than one. One possible reason can be wage rigidity in the formal sector. However, for trade taxes, short-term buoyancy is significantly higher than long-term buoyancy. The speed of adjustment for trade taxes is the lowest among all taxes, i.e., speed of adjustment toward its long-term equilibrium is relatively slow.

We further studied whether tax buoyancies have changed over time in sub-Saharan Africa against the background of tax reforms introduced by many countries since the late 1990s. Consequently, we divided our sample evenly into two periods, 1980-1998 and 1999-2017. ${ }^{15}$ This way we get the largest number of observations for each time segment which allows us to apply dynamic fixed effects estimation.

\footnotetext{
13 We follow the same approach as used by McNabb (2018). Hausman test evaluates the consistency of an estimator when compared to an alternative, less efficient estimator which is already known to be consistent. Here in our case, under the null hypothesis, both estimators (MG and PMG) are consistent, but PMG is efficient. If we reject the null hypothesis, it means that PMG is inconsistent, and MG is preferred. Otherwise, PMG is preferred.

14 To make the panel more balanced, we drop 4 countries in our sample.

15 Ideally, we would have liked to identify years with a dummy when tax reforms were implemented in SSA. Unfortunately, such data are not available. The one that exists for 45 emerging and low-income countries covers only 12 countries in SSA and that too for 2000-2015 period (Akitoby et al., 2019). This left us with an imperfect means of dividing the sample into two segments to capture the impact of tax reforms in recent years. Since the bulk of major tax policy changes in SSA countries were initiated in 1990s (Gillis, 2001), the post-1999 period captures their impact on tax buoyancy.
} 


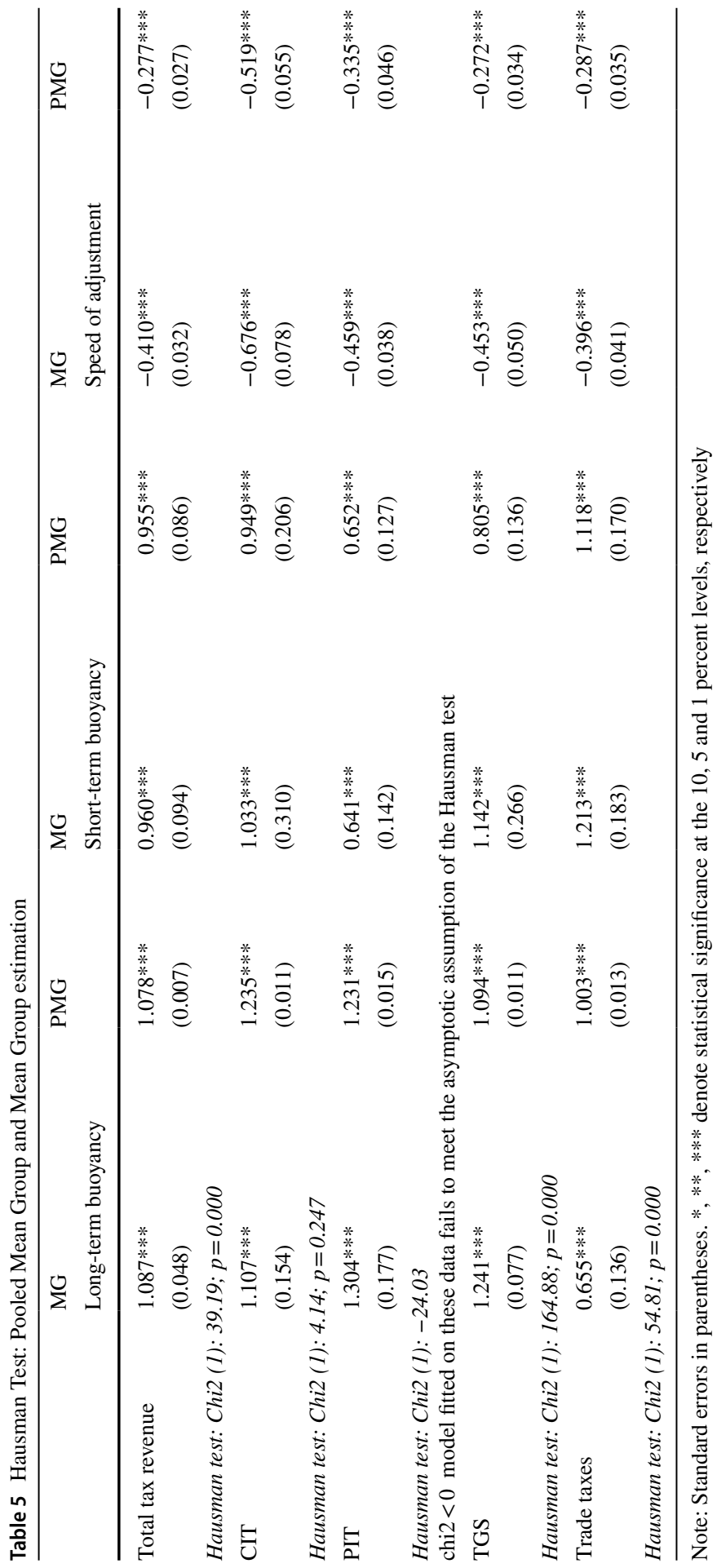




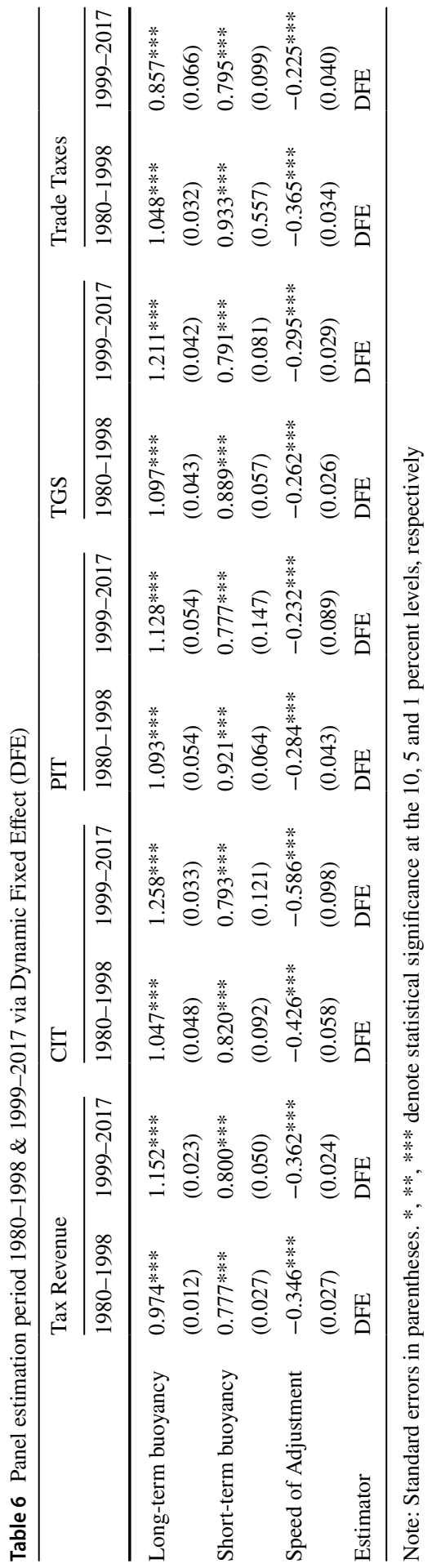


Table 7 Tax Buoyancy over the Business Cycle

\begin{tabular}{|c|c|c|c|c|c|}
\hline & \multicolumn{2}{|c|}{ Long-term buoyancy } & \multicolumn{2}{|c|}{ Short-term buoyancy } & \multirow{2}{*}{ Estimator } \\
\hline & Expansion & Contraction & Expansion & Contraction & \\
\hline \multirow[t]{2}{*}{ Total tax revenue } & $1.343^{* * * *}$ & $0.827 * *$ & $0.916 * * *$ & $0.469 * * *$ & \multirow[t]{2}{*}{ MG } \\
\hline & 0.3 & 0.346 & 0.093 & 0.099 & \\
\hline \multirow[t]{2}{*}{ CIT } & $1.235^{* * * *}$ & $1.152 * * *$ & $0.718 * *$ & 0.128 & \multirow[t]{2}{*}{ PMG } \\
\hline & 0.011 & 0.031 & 0.29 & 0.252 & \\
\hline \multirow[t]{2}{*}{ PIT } & $1.136^{* * *}$ & -1.71 & 0.336 & 0.069 & \multirow[t]{2}{*}{ MG } \\
\hline & 0.122 & 2.058 & 0.212 & 0.207 & \\
\hline \multirow[t]{2}{*}{ TGS } & $1.242^{* * *}$ & $0.611^{* * *}$ & $1.147 * * *$ & $0.394 * * *$ & \multirow[t]{2}{*}{ MG } \\
\hline & 0.078 & 0.134 & 0.264 & 0.106 & \\
\hline \multirow[t]{2}{*}{ Trade taxes } & $0.634 * * *$ & $0.278 * * *$ & $1.163^{* * * *}$ & $0.345 * * *$ & \multirow[t]{2}{*}{ MG } \\
\hline & 0.141 & 0.1 & 0.193 & 0.127 & \\
\hline
\end{tabular}

Note: Standard errors in parentheses. ${ }^{*}, * *, * * *$ denote statistical significance at the 10,5 and 1 percent levels, respectively

If estimates in the latter time period turned out to be higher, it would suggest that tax reforms implemented since 1999 have contributed to enhancing tax buoyancy. Because the resulting two time periods are relatively short, it is not possible to use MG or PMG and we are forced to rely instead on the DFE estimator. Results are displayed in Table 6.

Results suggest that, for overall taxes and most tax components, there is an increase in long-term buoyancy during the 1999-2017 period, except for trade taxes. The latter result is understandable given the declining reliance on trade taxes in SSA countries. Results suggest that structural improvements in tax systems in the second period are indeed having a tangible impact on tax buoyancies.

\subsubsection{The role of business cycle}

After estimating long-run and short-run buoyancies, we explore whether the stabilizing role of taxation (captured by the short-run buoyancy) and the fiscal sustainability role (captured by long-term buoyancy) vary during periods of economic expansion and economic contraction. We re-estimate Eq. (4) where a recession dummy indicating the state of the economy is included in additive form. "rec" $=1$ if nominal GDP growth $<0$ (contraction), "rec" $=0$ if nominal GDP growth $>0$ (expansion). Results are displayed in Table 7.

$$
\begin{aligned}
\Delta \operatorname{lnTax}_{i, t}= & \gamma\left(\operatorname{lnTax}_{i, t-1}-\beta_{\text {expansion }} \cdot(1-\mathrm{rec}) \cdot \operatorname{lnGDP}_{i, t-1}-\beta_{\text {contraction }} \cdot \operatorname{rec} \cdot \operatorname{lnGDP}_{i, t-1}\right) \\
& +\theta_{\text {expansion }} \cdot(1-\mathrm{rec}) \cdot \Delta \operatorname{lnGDP}_{i, t}+\theta_{\text {contraction }} \cdot \operatorname{rec} \Delta \operatorname{lnGDP}_{i, t}+\mu_{i}+\varepsilon_{i t}
\end{aligned}
$$

To better explore whether tax buoyancy varies depending on the phase of the business cycle, the following alternative short-run regression is estimated:

$$
\Delta \operatorname{lnTax} i, t=\mu_{i}+\beta_{1}^{\text {contraction }} \cdot Y\left(z_{i t}\right) \cdot \Delta \operatorname{lnGDP}_{i, t-1}+\beta_{2}^{\text {expansion }} \cdot\left[1-Y\left(z_{i t}\right)\right] \cdot \Delta \operatorname{lnGDP}_{i, t-1}+\varepsilon_{i, t}^{k}
$$


Table 8 Asymmetric short-term buoyancy over the business cycle

\begin{tabular}{lcc}
\hline & Expansion & Contraction \\
\hline Total tax revenue & $0.009^{* * *}$ & 0.014 \\
& $(0.003)$ & $(0.008)$ \\
CIT & $0.014^{*}$ & 0.020 \\
& $(0.007)$ & $(0.016)$ \\
PIT & 0.006 & 0.015 \\
& $(0.005)$ & $(0.013)$ \\
TGS & 0.003 & 0.009 \\
& $(0.003)$ & $(0.010)$ \\
Trade taxes & $0.004^{*}$ & 0.014 \\
& $(0.003)$ & $(0.010)$ \\
\hline
\end{tabular}

Note: OLS estimation with country and time effects included but omitted for reasons of parsimony. Constant term also omitted. Robust standard errors clustered at the country level in parentheses. $*$, **, *** denote statistical significance at the 10,5 and 1 percent levels, respectively

with $Y\left(z_{i t}\right)=\frac{\exp \left(-\gamma z_{i t}\right)}{1+\exp \left(-\gamma z_{i t}\right)}, \gamma>0$ where $z$ is an indicator of the state of the economy (using the real GDP growth ${ }^{16}$ ) normalized to have zero mean and unit variance. The remainder of the variables and coefficients are defined as before. This approach is equivalent to the smooth transition autoregressive (STAR) model developed by Granger and Teravistra (1993) and has recently been employed by Dudine and Jalles (2018) on a larger heterogeneous sample study. ${ }^{17}$ Results are displayed in Table 8.

Results from Table 7 suggest that both long-term buoyancy and short-term buoyancy are smaller during economic contractions. Lower short-term buoyancy during contraction indicates that the tax system is not working well as an automatic stabilizer in SSA. This effect is more significant for certain tax categories-TGS and trade taxes. Table 8 confirms - by means of alternatively estimating Eq. (5) - that buoyancy is smaller during contractions than during times of economic expansions, in particularly CIT and trade taxes. This result is contrary to that found in Dudine and Jalles (2018) for a much larger sample of countries. It is also at odds with the Furceri and Jalleś (2016) finding that points to an overall impact of fiscal stabilization (measured as the amount of fiscal counter-cyclicality) being larger during recessionary periods.

\footnotetext{
16 As a robustness check, we also consider recessions identified as: (i) episodes with a negative output gap; (ii) those produced by the Harding and Pagan (2002) algorithm to identify economic turning points. Results are available from the authors upon request. Note that regarding the use of the output gap, however, for our sample of SSA countries the IMF WEO output gap limits us on the total number of observations. Even constrained by data availability, all results reassuringly remain qualitatively similar.

17 The main advantage of this approach relative to estimating SVARs for each regime is that it considers a larger number of observations to compute the impulse response functions, making the responses more stable and precise.
} 


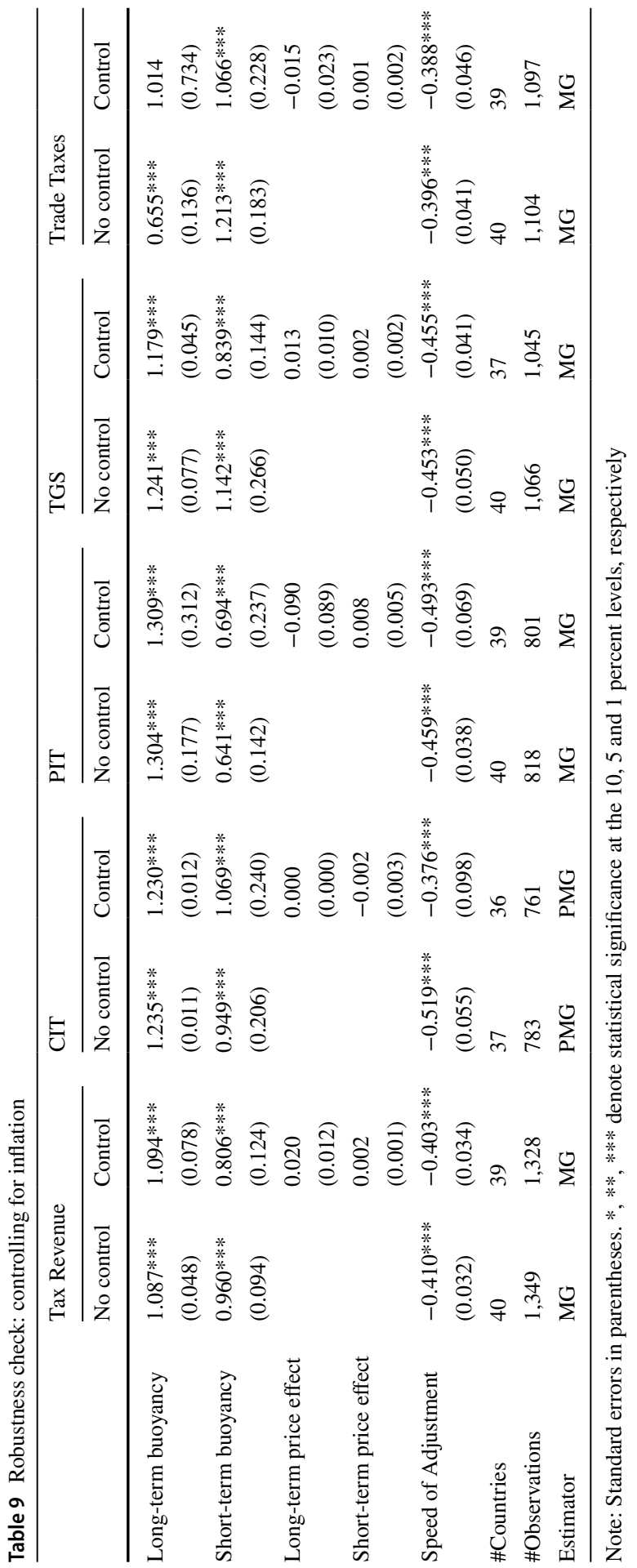


Table 10 Robustness Check: controlling for tax rate

\begin{tabular}{|c|c|c|c|c|}
\hline & \multicolumn{2}{|l|}{ CIT } & \multicolumn{2}{|l|}{ PIT } \\
\hline & No control & Control & No control & Control \\
\hline Long-term buoyancy & $\begin{array}{l}1.093 * * * \\
(0.025)\end{array}$ & $\begin{array}{l}1.082 * * * \\
(0.028)\end{array}$ & $\begin{array}{l}1.205 * * * \\
(0.058)\end{array}$ & $\begin{array}{l}1.166^{* * * *} \\
(0.047)\end{array}$ \\
\hline Short-term buoyancy & $\begin{array}{l}0.861 * * * \\
(0.062)\end{array}$ & $\begin{array}{l}0.854 * * * \\
(0.065)\end{array}$ & $\begin{array}{l}0.941 * * * \\
(0.059)\end{array}$ & $\begin{array}{l}0.950 * * * \\
(0.064)\end{array}$ \\
\hline Speed of Adjustment & $\begin{array}{l}-0.423 * * * \\
(0.028)\end{array}$ & $\begin{array}{l}-0.437 * * * \\
(0.030)\end{array}$ & $\begin{array}{l}-0.173 * * * \\
(0.022)\end{array}$ & $\begin{array}{l}-0.246^{* * * *} \\
(0.030)\end{array}$ \\
\hline Estimator & DFE & DFE & DFE & DFE \\
\hline
\end{tabular}

Note: Standard errors in parentheses. *,**, *** denote statistical significance at the 10,5 and 1 percent levels, respectively

\subsubsection{Controlling for inflation}

As a robustness check, we also added inflation as a control variable to assess whether tax buoyancy is independent of price changes. If it is, the same relationship would be obtained if real variables were used instead. Results in Table 9 show the coefficients for long-term buoyancy remain unchanged. Hence, long-term tax buoyancy appears neutral with respect to inflation, meaning long-term tax buoyancy in real terms is not significantly different from its nominal value. However, the coefficients of short-term buoyancy of total tax revenue, TGS and trade taxes are now smaller than before, meaning that tax buoyancy in real terms is smaller than the corresponding nominal value for these taxes. Short-term tax buoyancy of PIT and CIT remains unchanged.

\subsubsection{Controlling for tax rates}

A second robustness exercise pertains to controlling for discretionary tax changes made by governments during the period under study. Due to the limited availability of tax rate data, we only estimate tax elasticity of PIT and CIT. We compiled data of changes in these two taxes during 1990-2017. ${ }^{18}$ Results including and excluding tax rates as a control are displayed in Table 10. Long-term buoyancy shows a slight decline after controlling for tax rates. The rest of the results remain broadly the same.

\footnotetext{
${ }^{18}$ We chose dynamic fixed effect (DFE) after performing Hausman test. Another reason for choosing DFE estimator is that PMG requires longer time span for which we lack data.
} 


\section{What considerations affect tax buoyancy across countries}

In this section, we study the factors that influence cross-country differences in longterm buoyancy. The first variable included in the analysis is the share of value added by agriculture (as a share of GDP). Tanzi and Zee (2000) suggest that a large share of agriculture is associated with a smaller PIT and TGS. The same conclusions were reached by Ahmad and Stern (1991), Teera and Hudson (2004), and Stotsky and Wolde-Mariam (1997). Since agriculture is a difficult sector to tax, we expect a high share of agriculture to be associated with low tax buoyancy. The second variable we consider is the size of shadow economy. Shadow economy comprises economic activity that is undeclared to the tax authorities. An economy with a high share of shadow economy is likely to be associated with low tax buoyancy. The third variable included in our analysis is the size of central government debt as a share of GDP. A high level of debt reflects weak fiscal discipline and concerns about fiscal sustainability. It could suggest excessive government spending which does not add to economic growth. These considerations could adversely impact taxpayers' incentive to honor their tax obligations (Gupta \& Plant, 2019). The fourth variable we test is the prevalence of corruption-defined as the abuse of public office for private gain. A high incidence of corruption reflects weak government institutions. We also include CPIA efficiency of revenue mobilization rating as a proxy for strength of prevailing tax institutions in the country. Finally, we test whether incidence of a conflict affects tax buoyancy. ${ }^{19}$

We estimate the country-specific average of each indicator and then compute the cross-country median for each country in our sample. We then split the sample between those countries above or below the median and create a dummy variable taking value 1 when the level of the indicator is above the median. Finally, we take the estimated long-term buoyancy coefficients presented in Table 2 as our dependent variable. We estimate the following regression by OLS:

$$
\begin{aligned}
\hat{\beta}_{i}= & \alpha_{i}+\varphi_{1} \text { debt }_{i}+\varphi_{2} \text { corruption }_{i}+\varphi_{3} \text { agriculture }_{i}+\varphi_{4} \text { shadow economy }_{i} \\
& +\varphi_{5} \text { efficiency of revenue mobilization }_{i}+\varphi_{6} \text { conflict }_{i}+\varepsilon_{i}
\end{aligned}
$$

where $\hat{\beta}_{i}$ is an estimate of the long-term tax buoyancy of country $i, \alpha_{i}$ is constant, $\varepsilon_{i}$ is the error term. Central government debt, corruption index, share of agriculture in value added, the size of shadow economy, efficiency of revenue mobilization, and conflict are dummy variables created above. $\varphi_{1}-\varphi_{6}$ are coefficients of interest. Results

\footnotetext{
19 Data on share of agriculture, central government debt, and CPIA efficiency of revenue mobilization rating $(1=$ low to $6=$ high $)$ are taken from WDI database. Data on shadow economy are taken from Medina et al. (2017). Corruption Perceptions Index (CPI) data is taken from Transparency International. The CPI, with its 0-100 scale, scores and ranks countries/territories based on how corrupt a country's public sector is perceived to be by experts and business executives, where a 0 equals the highest level of perceived corruption and 100 equals the lowest level of perceived corruption. We then take the inverse of CPI as our indicator of corruption. Data on conflict is taken from the World Bank Global Spread of Conflict By Country And Population dataset. The indicator is coded 1 if the country is affected by ongoing conflict or experienced conflict in at least one calendar year during the past 10 years.
} 
Table 11 Determinants of Tax buoyancy: Total Tax Revenue

\begin{tabular}{lllllll}
\hline Specification & 1 & 2 & 3 & 4 & 5 & 6 \\
\hline Central government debt & $-0.199 * * *$ & $-0.233^{* * *}$ & $-0.194 * * *$ & $-0.173^{* * *}$ & $-0.180^{* * *}$ & $-0.198^{* * *}$ \\
& $(0.050)$ & $(0.049)$ & $(0.050)$ & $(0.057)$ & $(0.044)$ & $(0.062)$ \\
Share of Agriculture & 0.035 & & & & & 0.039 \\
& $(0.049)$ & & & & & $(0.045)$ \\
Shadow Economy & & $-0.082^{*}$ & & & & -0.042 \\
& & $(0.048)$ & & & & $(0.061)$ \\
Corruption & & & -0.052 & & & -0.052 \\
& & & $(0.050)$ & & & $(0.050)$ \\
CPIA efficiency & & & & 0.024 & & -0.011 \\
& & & & $(0.057)$ & & $(0.049)$ \\
Conflict & & & & & 0.069 & 0.051 \\
Constant & $1.165^{* * *}$ & $1.234^{* * *}$ & $1.207 * * *$ & $1.168 * * *$ & $1.147 * * *$ & $1.192^{* * *}$ \\
& $(0.041)$ & $(0.044)$ & $(0.030)$ & $(0.054)$ & $(0.032)$ & $(0.061)$ \\
\#Observations & 25 & 24 & 25 & 22 & 25 & 21 \\
$R$-squared & 0.436 & 0.565 & 0.451 & 0.355 & 0.467 & 0.541 \\
\hline
\end{tabular}

Note: Standard errors in parentheses. ${ }^{*}, * *, * * *$ denotestatistical significance at the 10,5 and 1 percent levels, respectively

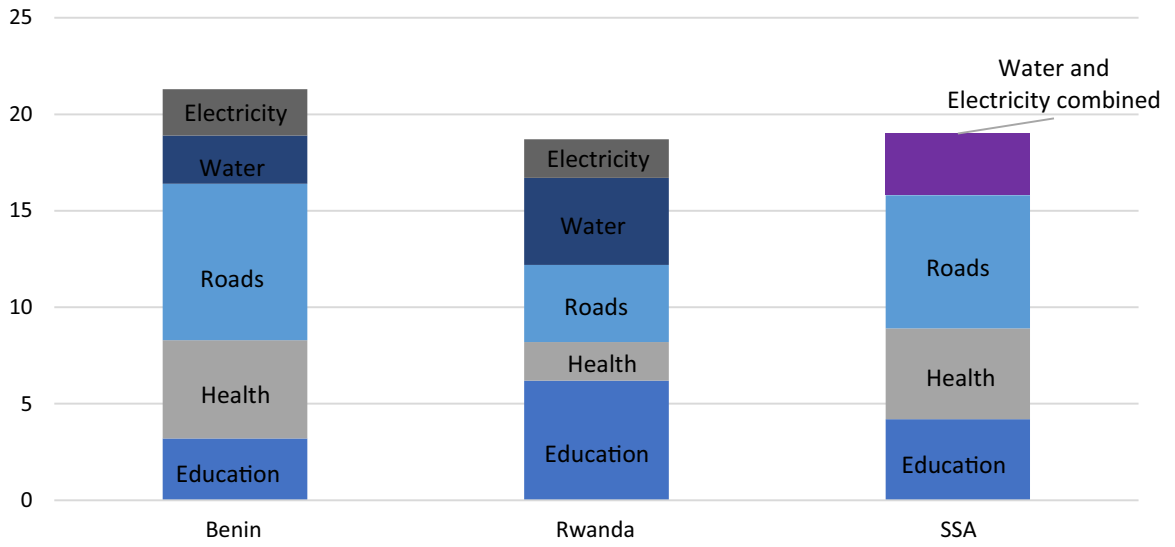

Fig. 8 Estimates for the Additional Spending in 2030, by Sector (Percent of 2030 GDP). Note: The median SSA country faces additional spending of about 19 percent of GDP. SSA country average estimates are only available for education, health and roads

are displayed in Table 11. Both central government debt and shadow economy have a negative impact on tax buoyancy. A large shadow economy undermines tax collections, thus associated with low tax buoyancy. The coefficients attached to the 
Table 12 Projected increases in Tax-to-GDP ratio by 2030 in SSA, Benin and Rwanda

Tax-to-GDP ratio in Estimated tax Projected Tax-to-GDP ratio Increase in 2016 (in percent) buoyancy in 2030 (in percent) Tax-to-GDP

ratio

\begin{tabular}{lrrrr}
\hline SSA & 15.8 & 1.08 & 16.6 & 0.8 \\
Benin & 9.2 & 1.18 & 10.6 & 1.4 \\
Rwanda & 15.5 & 1.13 & 18.7 & 3.2 \\
\hline
\end{tabular}

share of agriculture, corruption, efficiency of revenue mobilization and conflict are not statistically significant. Thus, the institutional quality as captured by corruption index and efficiency of revenue mobilization is not particularly relevant to reactions of taxes to GDP changes in SSA countries.

\section{Estimation of additional revenue generated by 2030}

As mentioned earlier, the IMF has estimated that financing the SDGs in LICs will require tax-to-GDP ratios to grow by at least 5 percent by 2030 . An average of 21.3 percent of GDP and 18.7 percent of GDP of additional spending is required for Benin and Rwanda, respectively, in order to achieve the SDGs in five areas (education, health, roads, electricity, water and sanitation) by 2030 .

Benin would need to spend additional 3.2 percent of its GDP on education, 5.1 percent of its GDP on health and 2.5 percent of GDP on water (Fig. 8) (see Prady \& Sy, 2019). For Rwanda, required spending to meet the SDGs is the largest in education, estimated at 6.2 percent of 2030 GDP. Additional required spending is estimated at about 4 percent of 2030 GDP on roads, 2 percent of GDP on health, 2 percent of GDP on electricity and 4.5 percent of GDP on water (Fig. 8).

Given the tax-to-GDP ratio for 2016, the projected GDP growth, and our estimates of long-term buoyancy, we can calculate tax revenue growth for sub-Saharan Africa, Benin, and Rwanda during 2016 and 2030 (Table 12). ${ }^{2021}$ Of course, out-ofsample projections are fraught with severe limitations, and estimates presented here should therefore be viewed as highly tentative.

The tax-to-GDP ratio in Benin would grow to 10.6 percent (an increase of 1.4 percent) and in Rwanda to 18.7 percent (an increase of 3.2 percent). The tax-to-GDP

\footnotetext{
${ }^{20}$ We are assuming that the downward revisions in SSA growth are temporary.

$21\left(\frac{\mathrm{Tax}}{\mathrm{GDP}}\right)_{i, n}=\left(\frac{\mathrm{Tax}}{\mathrm{GDP}}\right)_{i, m} * \prod_{j=m+1}^{n}\left(\frac{1+\text { buoyancy }_{i}{ }^{*} \mathrm{GDP}_{\text {growth }} \text { rate }_{i j}}{1+\mathrm{GDP}_{\text {growth }} \text { rate }_{i j}}\right), j=m+1, \ldots n ;\left(\frac{\mathrm{Tax}}{\mathrm{GDP}}\right)_{i, n}$ denotes tax-toGDP ratio of country $\mathrm{i}$ in year $n,\left(\frac{T a x}{G D P}\right)_{i, m}$ denotes tax-to-GDP ratio of country $\mathrm{i}$ in year $\mathrm{m}$, buoyancy $\mathrm{i}_{\mathrm{i}}$ denotes the long-term buoyancy estimated for country $i$, GDP growth rate ${ }_{i j}$ denotes GDP growth rate of country $i$ in year $j$. In our specification, $m=2016, n=2030$. GDP growth data comes from the International Monetary Fund, World Economic Outlook Database, October 2019. We use a simple 10-year (2009-2018) moving average as the predicted GDP growth rate after 2018. Tax-to-GDP ratio in year 2016 comes from ICTD dataset.
} 
ratio for SSA as a region would grow modestly by 0.8 percent. In all cases, incremental taxes generated by 2030 would fall short of the average 5 percent of GDP additional revenues needed by LICs to finance the SDGs, and the shortfall would be large for two countries (Rwanda and Benin) for which detailed resource estimates exist. This suggests that it is imperative that countries in sub-Saharan Africa continue to implement tax reforms to make their systems more responsive to income changes. At the same time, policymakers in Africa must complement tax-enhancing efforts with those directed at improving the quality of spending. It is possible to generate up to 3 percent of GDP in resources by focusing on improving the efficiency of existing budget allocations (Gupta, 2018).

\section{Concluding remarks and future research}

In this paper, we estimated the short- and long-term tax buoyancies of 44 SSA countries between 1980 and 2017 using both time series and panel data techniques. Short-term buoyancy of PIT is significantly less than one. This could be attributable to wage rigidity in the formal sector. The estimated long-term buoyancy suggests that most taxes are progressive, except for those on trade. Overall, the robustness checks show that tax buoyancy is neutral to discretionary tax changes. The good news is that there is an increase in long-term buoyancy in the more recent period in reflection of tax reforms implemented by SSA countries. The future tax reforms would need to capture the changing economic structure to improve buoyancy. The cross-country determinants of long-term tax buoyancy suggest that both central government debt and shadow economy exert downward pressure on tax buoyancy. Our estimates suggest that domestic tax revenues generated by 2030 would not be adequate to cover spending needed to achieve the SDGs in SSA and two countries, Benin and Rwanda. The revenue shortfall could be larger if the spread of COVID19 were to dampen SSA's growth prospects over a long period. It could also delay implementation of critical tax reforms as countries seek to mitigate the virus' impact through a fiscal stimulus.

Future research could study how tax buoyancy is affected by tax reforms by estimating time-varying long-term tax buoyancies in SSA countries and then assessing their determinants, including discretionary tax reforms.

\section{Appendix}

See Tables 13, 14, 15 and 16. 


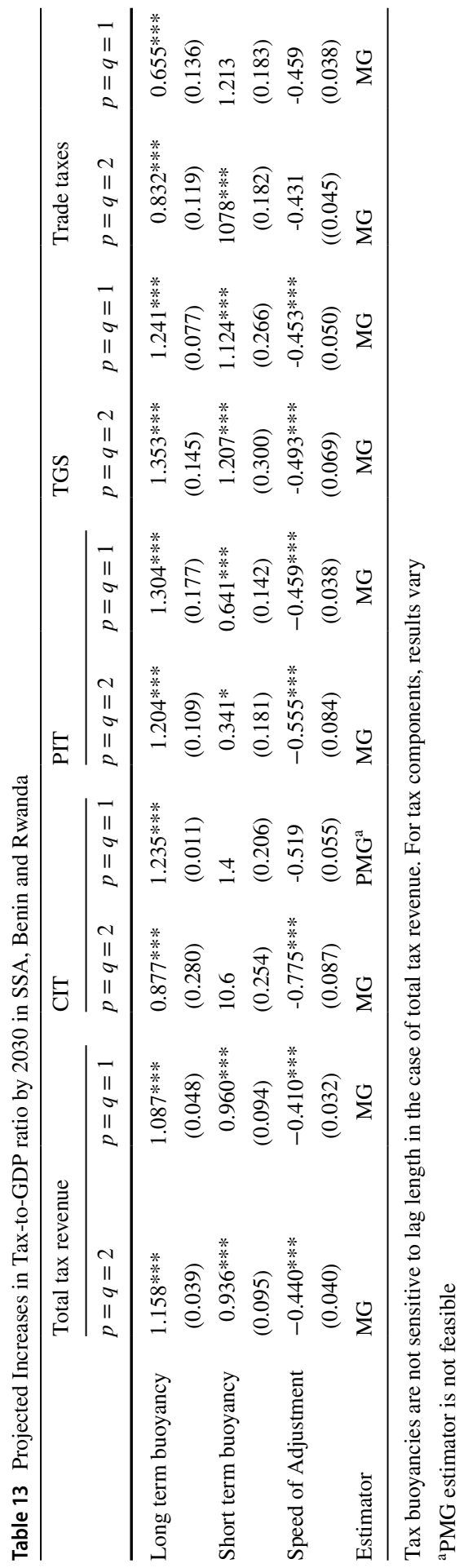




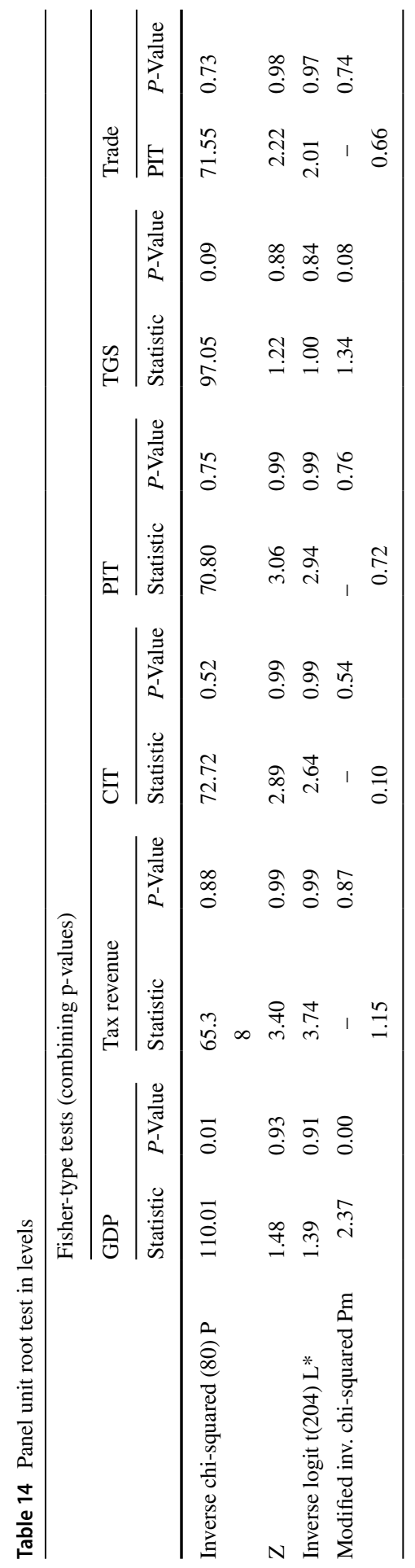




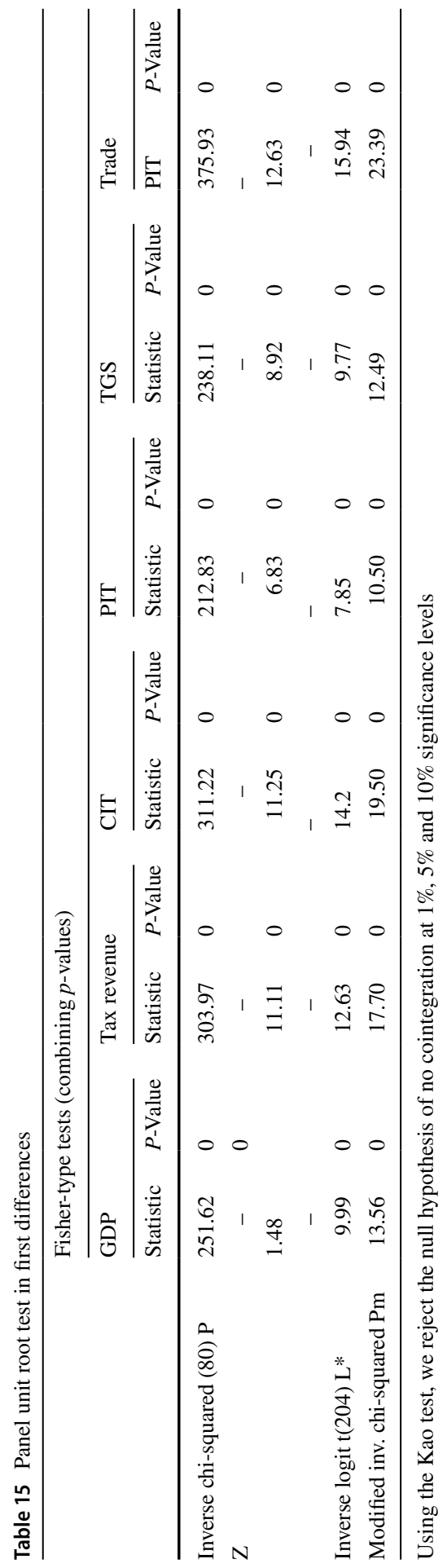




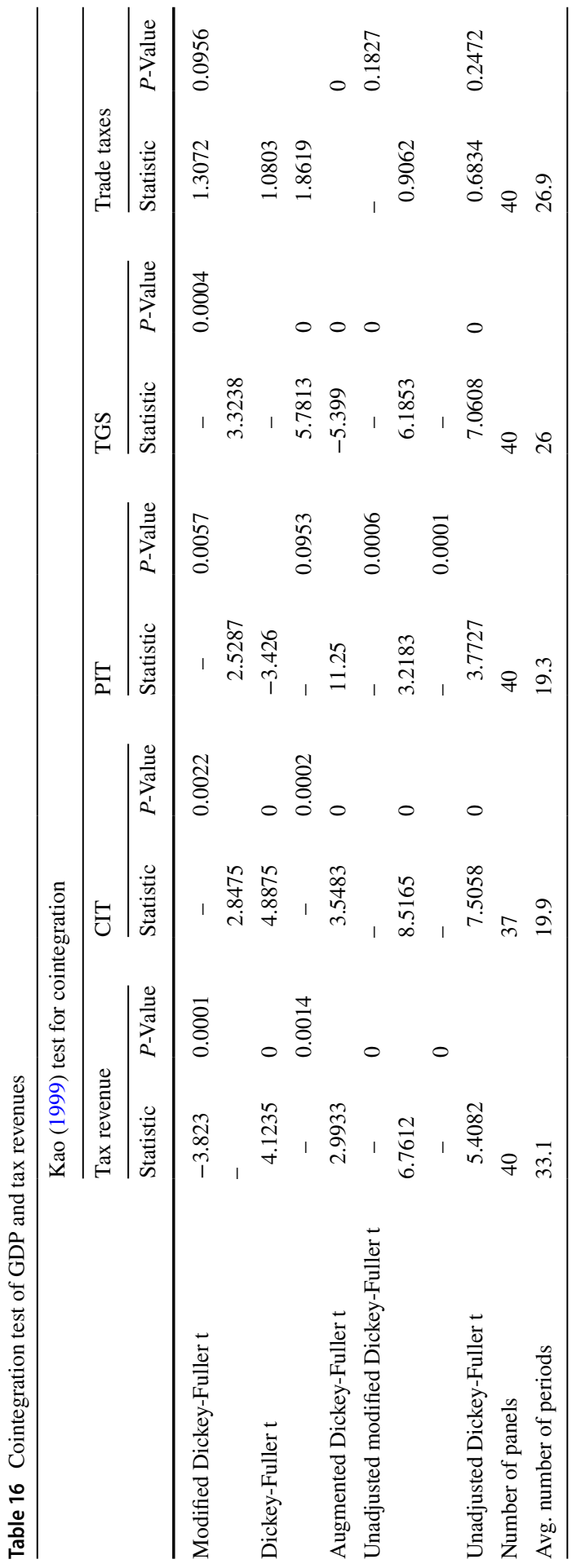


Acknowledgements We would like to thank two anonymous referees as well as Masood Ahmed, Michael Clemens, and Mark Plant for valuable suggestions on an earlier version of the paper. We are grateful to the Bill \& Melinda Gates Foundation for financial support. The usual disclaimer applies, and any remaining errors are the authors' own responsibility.

\section{References}

Ahmad, E., \& Stern, N. (1991). The theory and practice of tax reform in developing countries. Cambridge University Press.

Akitoby, B., Baum, A., Hackney, C., Harrison, O., Primus, K., Salins, V. (2019). Tax revenue mobilization episodes in developing countries. Policy Design and Practice, 3(1).

Bayu, T. (2015). Analysis of tax buoyancy and its determinants in Ethiopia (Cointegration Approach). Journal of Economics and Sustainable Development, 6(3), 182-194.

Bekoe, W., Danquah, M., \& Senahey, S. K. (2016). Tax reforms and revenue mobilization in Ghana. Journal of Economic Studies, 43(4), 522-534.

Belinga, V., Benedek, M.D., De Mooij, R.A. \& Norregaard, M.J. (2014). Tax buoyancy in OECD countries. IMF Working Paper WP/14/110, Washington.

Benedek, D., Crivelli, E., Gupta, S., \& Muthoora, P. (2014). Foreign aid and revenue: Still a crowdingout effect?. FinanzArchiv/Public Finance Analysis, pp 67-96.

Brückner, M. (2012). An instrumental variables approach to estimating tax revenue elasticities: Evidence from Sub-Saharan Africa. Journal of Development Economics, 98(2), 220-227.

Clements, B., Gupta, S., \& Inchauste, G. (2004). Helping countries develop: the role of fiscal policy. International Monetary Fund.

Crivelli, E., \& Gupta, S. (2014). Resource blessing, revenue curse? Domestic revenue effort in resourcerich countries. European Journal of Political Economy, 35, 88-101.

Deli, Y., Rodriguez, A.G., Kostarakos, I., \& Varthalitis, P. (2018). Dynamic tax revenue buoyancy estimates for a panel of OECD countries. ESRI Working Paper, No. 592. Dublin, Ireland: The Economic and Social Research Institute.

Dudine, P., \& Jalles, J. T. (2018). How buoyant is the tax system? New evidence from a large heterogeneous panel. Journal of International Development, 30(6), 961-991.

Furceri, D., \& Jalles, J. T. (2016). Determinants and effects of fiscal stabilization: New evidence from time-varying estimates. IMF Working Paper forthcoming.

Gaspar, V., Jaramillo, L., \& Wingender, M.P. (2016). Tax capacity and growth: Is there a Tipping point? International Monetary Fund.

Gaspar, V., Amaglobeli, M.D., Garcia-Escribano, M.M., Prady, D., \& Soto, M. (2019). Fiscal policy and development: human, social, and physical investments for the SDGs. International Monetary Fund.

Gillis, M. (2001). Experience with the VAT. Policy Science, 34(2), 195-215.

Granger, C. W. J., \& Terasvirta, T. (1993). Modelling Nonlinear Economic Relationships. Oxford University Press.

Gupta, S. \& Plant, M. (2019). Enhancing Domestic Resource Mobilization: What are the Real Obstacles?" April 30, 2019. https://www.cgdev.org/blog/enhancing-domestic-resource-mobilizationwhat-are-real-obstacles.

Gupta, S. (2018). Merely collecting more taxes is not enough to achieve the SDGs, July 17, 2018. https:// www.cgdev.org/blog/merely-collecting-more-taxes-not-enough-achieve-sdgs.

Jalles, J. T. (2017). Tax Buoyancy in Sub-Saharan Africa: An empirical exploration. African Development Review, 29(1), 1-15.

Kao, C. (1999). Spurious regression and residual-based tests for cointegration in panel data. Journal of Econometrics, 90(1), 1-44.

Kargbo, B. I. B., \& Egwaikhide, F. O. (2012). Tax elasticity in Sierra Leone: A time series approach. International Journal of Economics and Financial Issues, 2(4), 432-447.

Kusi, N.K. (1998). Tax reform and revenue productivity in Ghana. African Economic Research Consortium Research Paper No. 74, Nairobi

Lagravinese, R., Liberati, P., Sacchi, A. (2020). Tax buoyancy in OECD countries: new empirical evidence, Journal of Macroeconomics, 63. 
McNabb, K. (2018). Tax Structures and economic growth: New evidence from the government revenue dataset. Journal of International Development, 30(2), 173-205.

Medina, L., Jonelis, A.W., \& Cangul, M. (2017). The Informal Economy in Sub-Saharan Africa: Size and Determinants. IMF Working Paper WP/17/156, Washington.

Mullins, P., Gupta, S., \& Liu, J. (2020), Domestic Revenue Mobilization in Low Income Countries: Where To From Here?. Center for Global Development Policy Paper 195, Washington

Osoro NE. (1993). Revenue productivity implications of tax reform in Tanzania. African Economic Research Consortium Research Paper No. 20, Nairobi

Pesaran, M. H., \& Smith, R. P. (1995). Estimating long-run relationships from dynamic heterogeneous panels. Journal of Econometrics, 68, 79-113.

Pesaran, M. H., Shin, Y., \& Smith, R. P. (1999). Pooled mean group estimation of dynamic heterogeneous panels. Journal of the American Statistical Association, 94(446), 621-634.

Prady, D., \& Sy, M. (2019). The spending challenge for reaching the SDGs in Sub-Saharan Africa: Lessons learned from Benin and Rwanda. IMF Working Paper WP/19/270, Washington.

Shikongo, A., Kakujaha-Matundu, O., \& Kaulihowa, T. (2019). Revenue productivity of the Tax System in Namibia: Tax buoyancy estimation approach. Journal of Economics and Behavioral Studies, 11(2 (J)), 112-119.

Stotsky JG, \& Wolde-Mariam A. (1997). Tax effort in sub-Saharan Africa. IMF Working Paper WP/97/107, Washington.

Tanzi, V., \& Zee, H. (2000). Tax policy for emerging markets: Developing countries. IMF Working Paper WP/00/35, Washington.

Teera, J. M., \& Hudson, J. (2004). Tax performance: A comparative study. Journal of International Development, 16(6), 785-802.

Publisher's Note Springer Nature remains neutral with regard to jurisdictional claims in published maps and institutional affiliations. 